УДК 332.1

Найденова Т.А.

ФГБОУ ВО «Сыктывкарский государственный университет

имени Питирима Сорокина», Сыктывкар, e-mail: NaydenovaTA@mail.ru

\title{
ОЦЕНКА СОСТОЯНИЯ ПРОМЫШЛЕННОЙ ПОЛИТИКИ СЕВЕРНОГО РЕГИОНА
}

Ключевые слова: регион, промышленная политика, промышленное производство, обрабатывающая промышленность, государственно-частное партнерство.

В статье подчеркнута необходимость исследования состояния промышленной политики страны в целом и каждого отдельно взятого региона для разработки мероприятий по коренному изменению ее содержания и подходов к ее реализации. Дана оценка состояния промышленной политики в Республике Коми. Сделан вывод о необходимости модернизации промышленного производства в республике, в первую очередь, в обрабатывающих видах экономической деятельности. Предложены меры, которые выстраивают системный подход к решению задач роста промышленного производства на данной территории. Они адекватны сложившейся ситуации, направлены на поиск возможностей развития несырьевого сектора экономики, развитие обрабатывающей промышленности, что особенно важно в условиях санкций со стороны США и стран Евросоюза и необходимости проведения политики импортозамещения.

\section{Naydenova T.A.}

Syktyvkar State University named after Pitirim Sorokin, Syktyvkar, e-mail: NaydenovaTA@mail.ru

\section{ESTIMATION OF THE CONDITION OF INDUSTRIAL POLICY OF THE NORTHERN REGION}

Keywords: region, industrial policy, industrial production, manufacturing industry, public-private partnership.

The article emphasizes the need to study the state of the industrial policy of the country as a whole and of each individual region for the development of measures for a fundamental change in its content and approaches to its implementation. An assessment of the state of industrial policy in the Komi Republic is given. The conclusion is made about the need to modernize industrial production in the country, primarily in the processing types of economic activity. The proposed measures that build a systematic approach to solving problems of growth of industrial production in the area. They are adequate to the current situation, aimed at finding opportunities for the development of the non-primary sector of the economy, development of the manufacturing industry, which is especially important in the context of sanctions imposed by the United States and the European Union countries and the need to implement an import substitution policy.

\section{Введение}

На современном этапе экономического развития обеспечение конкурентоспособности страны является важнейшей проблемой, характеризующей не только положение страны на мировом рынке, но и определяющей в значительной степени ее национальную безопасность. «Конкурентоспособность отдельно взятой страны зависит от склонности ее промышленности к инновациям и модернизации» [13, с. 205.]. Поэтому Правительством России взят курс на поиск новой парадигмы промышленного развития.

Необходимость «новой упаковки» для промышленной политики усиливается несколькими факторами [4, с.16-17]:

- введением секторальных технологических санкций, которые ограничива- ют приток технологий и оборудования в отдельных отраслях. С одной стороны, это ограничивает развитие отдельных отраслей в краткосрочной перспективе, а с другой, - в долгосрочной перспективе способствует развитию собственных производств и импортозамещению;

- введением санкций в финансовой сфере, которые ограничивают доступ российских фирм к мировым рынкам капитала, а соответственно, сужают имеющуюся ресурсную базу, что может служить существенным ограничением для развития отдельных отраслей российской экономики;

- развитием рисков ведения бизнеса, которые негативно влияют на деятельность организаций в России в силу вероятности мобилизационного вариан- 
та развития событий, а также снижают объем прямых иностранных инвестиций в страну;

- изменением условий торговли, которое привело к ослаблению рубля, что, в свою очередь, способствовало росту стоимости заимствований и ухудшению условий ведения бизнеса внутри страны.

Особенно остро вопрос об оценке состояния промышленной политики стоит в северных субъектах РФ, поскольку специфика промышленные систем на севере заключается в монопродуктовом характере, определяющем естественную сложность перехода промышленности на путь устойчивого развития. Кроме того, на структурную диверсификацию промышленности на региональном уровне могут влиять труднопрогнозируемые внешние компоненты.

В силу представленных аргументов проблематика статьи является актуальной.

Целью авторского исследования является разработка теоретико-методологических аспектов формирования и реализации промышленной политики субъекта РФ и оценка состояния промышленной политики северного региона - Республики Коми - для принятия эффективных управленческих решений по обеспечению устойчивого роста и поступательного развития региона.

\section{Материалы и методы исследования}

Определены следующие аспекты исследования:

1) теоретико-методологические подходы к раскрытию сущности промышленной политики;

2) методические подходы к оценке состояния промышленного развития региона;

3) прикладные аспекты.

Теоретико-методологические аспекты исследования включают:

- подходы к трактовке дефиниции «промышленная политика»;

- методическое обоснование механизма формирования и реализации промышленной политики;

- методологическое обоснование инструментов промышленной политики;

Методические подходы к оценке промышленной политики включают:

- разработку индикаторов и показателей оценки;
- оценку уровня развития промышленного производства в регионе.

Прикладные аспекты исследования касаются оценки состояния промышленной политики Республики Коми.

Методологически исследование опирается на труды отечественных ученых, посвященные оценке состояния промышленной политики на федеральном и региональном уровнях и выработке направлений ее активизации для решения стратегических задач, стоящих перед страной и регионом.

Ключевые методы исследования можно сгруппировать по этапам: логикоструктурный анализ, институциональный анализ, контент-анализ документов.

Несмотря на растущий интерес исследователей к индустриальному сектору экономики, что проявляется в многочисленных исследованиях различных его аспектов, до сих пор имеет место дискурс по вопросу трактовки данного экономического феномена.

Подходы к трактовке «промышленная политика» в академической среде и прикладных работах представлены в таблице 1.

Анализ подходов к трактовке дефиниции «промышленная политика» позволил сделать вывод о том, что это понятие сложное, многофункциональное. Авторы, как правило, отождествляют ее с механизмом реализации, либо определяют, как инструмент решения экономических и социальных задач. За рамками исследования осталась ее основная цель.

По-видимому, доктринальное определение дефиниции «промышленная политика» должно синтезировать основные методологические положения названных подходов, а, именно:

1) промышленная политика - инструмент макроэкономического регулирования;

2) промышленная политика - ключевой фактор достижения национальной конкурентоспособности;

3) определяющим вектором промышленной политики становится изменение ее модели - переход от экспортносырьевого типа к инновационному;

4) промышленная политика связана с инновационной, инвестиционной и структурной перестройкой промышленного производства. 
Подходы к определению дефиниции «промышленная политика»

\begin{tabular}{|c|c|}
\hline Автор & Определение \\
\hline Прайс В. [14] & $\begin{array}{l}\text { Промышленная политика - совокупность мер или мероприятий на нацио- } \\
\text { нальном уровне по направленному осуществлению или, наоборот, предот- } \\
\text { вращению определенных структурных сдвигов в экономике }\end{array}$ \\
\hline Кругман П.Р. [8] & $\begin{array}{l}\text { Промышленная политика - действия государства по привлечению ресурсов } \\
\text { в секторы экономики, важные для обеспечения экономического роста в бу- } \\
\text { дущем }\end{array}$ \\
\hline Родрик Д. [15] & $\begin{array}{l}\text { Промышленная политика - политика по изменению структуры экономики } \\
\text { (т.е. политика, направленная на формирование в экономике новых видов де- } \\
\text { ятельности, реализация которой приводит к ускорению развития экономики } \\
\text { и росту доходов) }\end{array}$ \\
\hline Всемирный банк [5] & $\begin{array}{l}\text { Промышленная политика - усилия правительства по изменению отраслевой } \\
\text { структуры экономики для стимулирования экономического роста на основе } \\
\text { повышения производительности труда }\end{array}$ \\
\hline ЮНИДО [20]. & $\begin{array}{l}\text { Промышленная политика-любое вмешательство государства, которое улуч- } \\
\text { шает бизнес-среду или изменяет структуру экономической деятельности и } \\
\text { направляет свои усилия на те сектора или на развитие тех технологий и ви- } \\
\text { дов деятельности, которые будут способствовать экономическому росту, или } \\
\text { росту общественного благосостояния. }\end{array}$ \\
\hline Кондратьев В. [7] & $\begin{array}{l}\text { Промышленная политика - система мер прямого и косвенного государствен- } \\
\text { ного регулирования инновационного, конкурентоспособного и эффективно- } \\
\text { го развития промышленности и устранения для реализации этой цели тех } \\
\text { препятствий, которые не могут быть преодолены естественным ходом со- } \\
\text { бытий, то есть механизмами саморегуляции рынка }\end{array}$ \\
\hline Смирнов Е. [17] & $\begin{array}{l}\text { Промышленная политика - комплекс мер государственного регулирования } \\
\text { экономических процессов на отраслевом и корпоративном уровнях, направ- } \\
\text { ленный на стимулирование инновационной активности, структурной пере- } \\
\text { стройки экономики и экономического роста }\end{array}$ \\
\hline Завадников В.О. [2] & $\begin{array}{l}\text { Промышленная политика-совокупность действий государства как институ- } \\
\text { та, предпринимаемых для оказания влияния на деятельность хозяйствующих } \\
\text { субъектов (предприятий, корпораций, предпринимателей и т.д.), а также на } \\
\text { отдельные аспекты этой деятельности, относящиеся к приобретению факто- } \\
\text { ров производства, организации производства, распределению и реализации } \\
\text { товаров, работ, услуг во всех фазах жизненного цикла его продукции }\end{array}$ \\
\hline $\begin{array}{l}\text { Татаркин А.И., } \\
\text { Романова О.А. [19] }\end{array}$ & $\begin{array}{l}\text { Промышленная политика - национальная промышленная политика, т.е. си- } \\
\text { стема отношений между государственными и муниципальными органами } \\
\text { власти, хозяйствующими субъектами, научными и общественными органи- } \\
\text { зациями по поводу формирования структурно-сбалансированной, конкурен- } \\
\text { тоспособной промышленности, интеллектуальное ядро которой представле- } \\
\text { но новейшим технологическим укладом }\end{array}$ \\
\hline Ивантер В.В. [9] & $\begin{array}{l}\text { Промышленная политика - система правовых, экономических, организаци- } \\
\text { онных и иных мер, осуществляемых органами государственной власти и на- } \\
\text { правленных на повышение эффективности промышленной деятельности и } \\
\text { конкурентоспособности выпускаемой продукции }\end{array}$ \\
\hline
\end{tabular}

Составлено автором с использованием $[2,5,7,8,9,14,15,17,19,20]$.

Учитывая вышесказанное определим промышленную политику как часть экономической политики государства, нацеленную на формирование высокотехнологичной, конкурентоспособной промышленности, позволяющей обеспечивать переход экономики страны от экспортно-сырьевого типа развития к инновационному типу развития, из- менить модель ее механизма, перейти от механизма поддержки наукоемких секторов (поддержка реструктуризации и модернизации традиционных отраслей, антикризисный механизм) к проектному подходу (институты развития, технологические платформы, кластерный подход, государственно-частное партнерство). 
В данном определении четко сформулирована цель промышленной политики и модель механизма ее реализации с учетом необходимости внедрения и реализации политики импортозамещения, получившей стартовый импульс от взаимного действия международных экономических санкций, в результате применения которых прекратился приток дешевого капитала, оборудования, инновационных технологий и одновременно, возникла необходимость изменения структуры экономики и повышения ее национальной конкурентоспособности.

Региональная промышленная политика, несомненно, является составной частью государственного аналога, при этом к ней предъявляются специфические требования и ограничения, исходя из темпов социально-экономического развития региона.

Однако определение дефиниции «региональная промышленная политика» не зафиксировано в законодательных актах РФ.

Определим региональную промышленную политику как региональную составляющую промышленной политики государства, представляющую собой систему мер, направленных на инновационные изменения в структуре промышленного производства в соответствии с выбранными целями и приоритетами стратегии развития субъекта РФ.

Механизм формирования и реализаичии промышленной политики Республики Коми

Успешность проведения промышленной политики во многом определяется продуманным механизмом ее формирования и реализации. Данный механизм, как и само понятие промышленной политики, претерпел существенные изменения. Он призван не только снизить негативные социальные последствия процесса трансформации промышленного комплекса территории, но и решить проблемы, являющиеся общими как для традиционных, так и для наукоемких отраслей (проблемы структурной безработицы, инфраструктурного обеспечения структурной перестройки промышленности, повышения «инновационноемкости» промышленного комплекса и т.д.).
Республика Коми имеет достаточно богатый опыт разработки и реализации промышленной политики. Логическая схема разработки региональной промышленной политики применительно к условиям Республики Коми, может быть использована как типовая схема региональной промышленной политики (рис. 1, 2).

Диапазон возможных инструментов промышленной политики

По мере усложнения экономики развивались инструменты промышленной политики - от простых, универсальных схем государственного субсидирования до сложных взаимосвязанных действий по развитию промышленных кластеров и обеспечению инфраструктуры экономического развития.

Программные инструменты включают государственные программы, региональные целевые программы, отраслевые целевые программы.

Научно-технические инструменты содержат научно-образовательные комплексы, центры компетенций, техническое регулирование.

Финансовые инструменты делятся на налоговые, кредитные, инвестиционные. Действенным механизмом государственной промышленной политики, обеспечивающим стимулирование развития, является установление льготного порядка налогообложения организаций промышленности. Кредитные инструменты включают предоставление бюджетных кредитов за счет бюджета. Инвестиционные инструменты - субсидии, субвенции, бюджетные инвестиции, венчурные инвестиции.

Инфраструктурные инструменты являются элементом новой промышленной политики: создание условий для формирования и развития региональных промышленных кластеров, создание технологических платформ, развитие информационной инфраструктуры.

Методические подходы к оценке промышленной политики

Для оценки эффективности промышленной политики используем две группы показателей:

1) показатели масштаба промышленного производства;

2) показатели эффективности промышленной политики [6, с. 370]. 


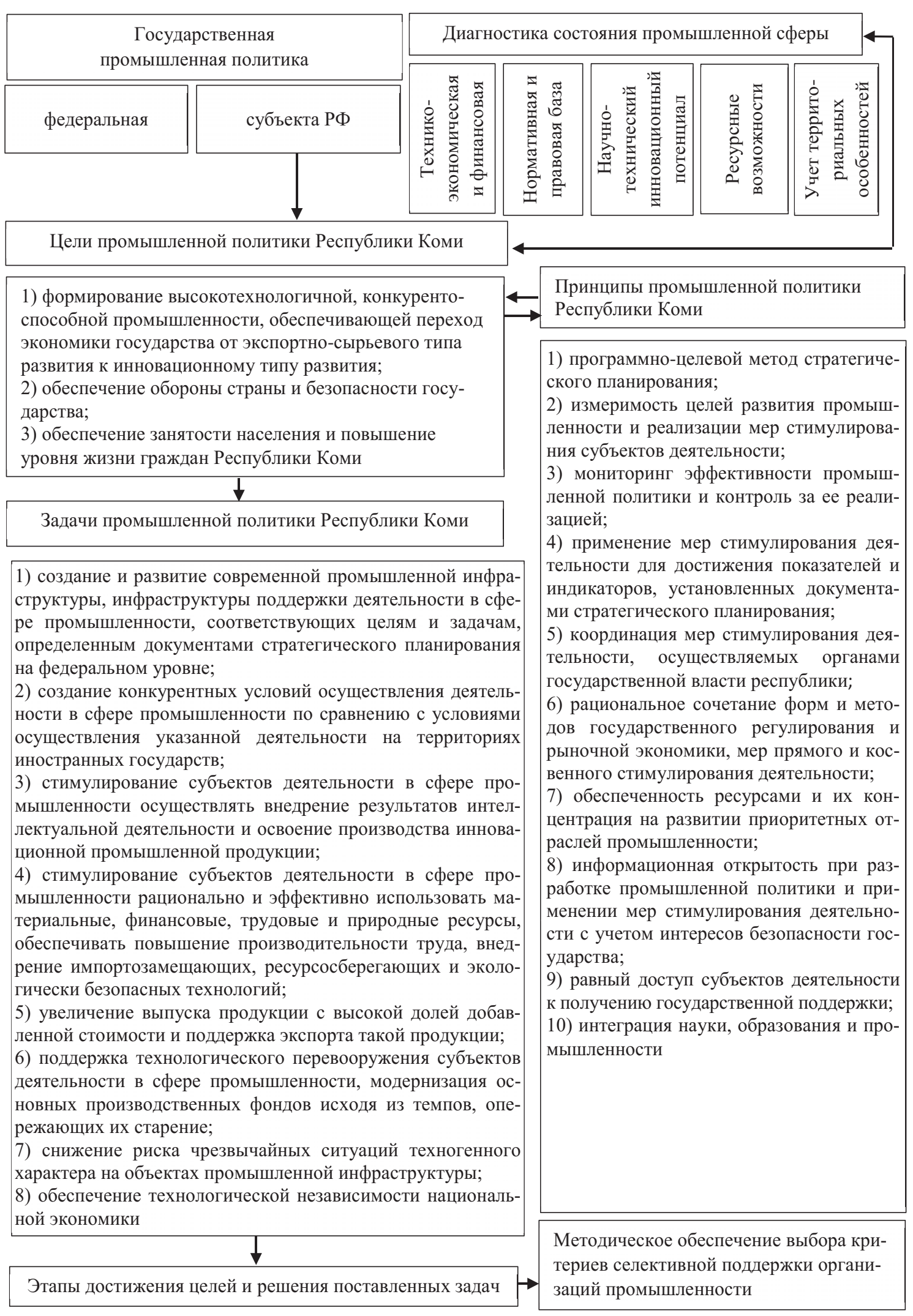

Рис. 1. Модель формирования промылиленной политики Составлено автором с использованием [18]. 


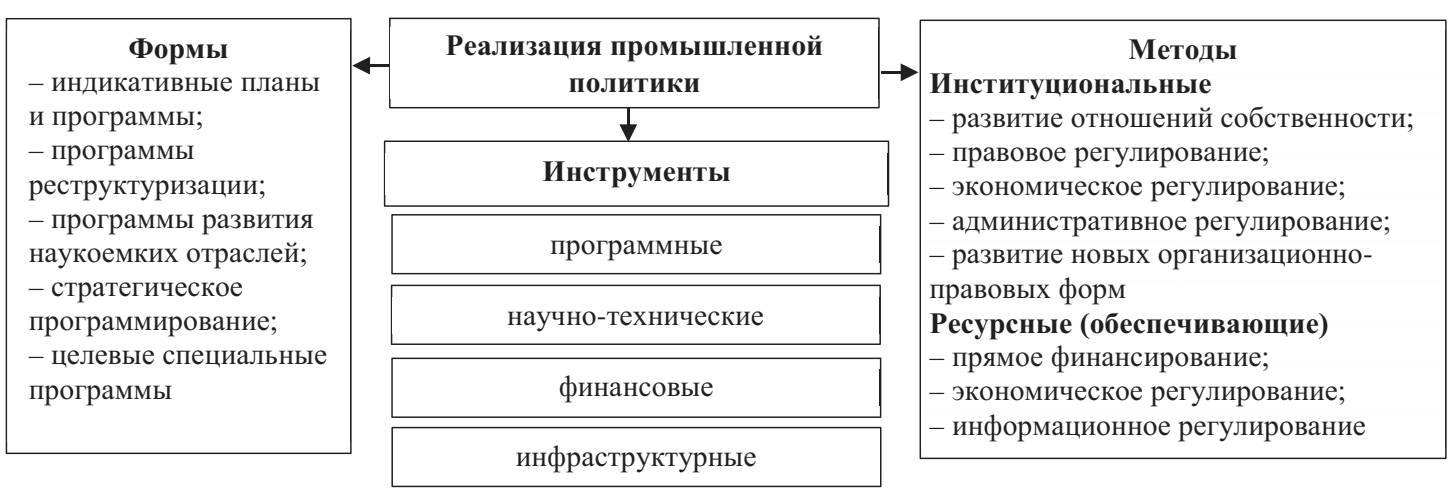

Рис. 2. Механизм реализации промышленной политики

Составлено автором с использованием [18].

Таблица 2

Индекс промышленного производства в РФ и Республике Коми, \%

\begin{tabular}{|l|c|c|c|c|c|c|c|c|c|}
\hline \multirow{2}{*}{ Субъект РФ } & \multicolumn{10}{|c|}{ Исследуемый период } \\
\cline { 2 - 11 } & 2005 & 2010 & 2011 & 2012 & 2013 & 2014 & 2015 & 2016 & 2017 \\
\hline РФ & 105,1 & 107,3 & 105,0 & 103,4 & 100,4 & 101,7 & 96,6 & 101,1 & 101,0 \\
\hline $\begin{array}{l}\text { Республика } \\
\text { Коми }\end{array}$ & 104,1 & 100,8 & 104,4 & 102,1 & 102,4 & 100,5 & 101,6 & 96,0 & 97,0 \\
\hline
\end{tabular}

Рассчитано по данным Территориального органа Федеральной службы государственной статистики по Республике Коми [Электронный ресурс]. URL: http://komi.gks.ru/ (дата обращения: 10.12.2018)

Масштаб промышленного производства оценим с использованием количественных индикаторов: индекс промышленного производства, объем отгруженных товаров собственного производства, выполненных работ и услуг собственными силами.

Эффективность развития промышленности характеризуют индикаторы: объем производства товаров, выполнения работ и услуг собственными силами на душу населения, доля промышленности в ВРП, доля обрабатывающей промышленности в ВРП, структура промышленного производства (доля обрабатывающих и добывающих производств в общем объеме промышленного производства).

Прикладные аспекты исследования

Оценим состояние промышленного производства в Республике Коми, используя указанные показатели и индикаторы (табл. 2).

Данные таблицы свидетельствуют о снижении темпов роста промышленного производства в 2017 г. по сравнению с 2005 г., что указывает на сжатие экономики республики, вызывает торможение всех процессов в целом. Одна- ко в 2017 г. наметилось незначительное оживление по сравнению с 2016 г.

В Республике Коми в 2017 г. имеет место рост объема отгруженных товаров собственного производства, выполненных работ и услуг собственными силами. Однако темпы роста данного показателя в республике значительно ниже российских $(3,2 \%$ - темп роста в 2017 г. по сравнению с 2005 г. в республике против 4,4\% по России) (табл. 3 ).

На темпы роста промышленного производства существенное влияние оказал спад по виду экономической деятельности «Добыча полезных ископаемых» (в 2017 г. по сравнению с 2005 г. на $14,1 \%)$. Другим фактором, определяющим состояние промышленного производства в республике, выступает уровень обеспечения электроэнергией, газом и паром. Снижение темпов роста производства по виду экономической деятельности «Производство и распределение электроэнергии, газа и воды» наметилось в 2015 г. и продолжилось в 2016 г. В 2017 г. имеет место незначительное улучшение ситуации в данном виде экономической деятельности. 
Объем отгруженных товаров собственного производства, выполненных работ и услуг собственными силами, млрд. руб.

\begin{tabular}{|l|c|c|c|c|c|c|c|c|c|}
\hline \multirow{2}{*}{ Субъект РФ } & \multicolumn{10}{|c|}{ Исследуемый период } \\
\cline { 1 - 11 } & 2005 & 2010 & 2011 & 2012 & 2013 & 2014 & 2015 & 2016 & 2017 \\
\hline РФ & 11934 & 25099 & 30833 & 34061 & 36154 & 39352 & 46350 & 47896 & 52649 \\
\hline $\begin{array}{l}\text { Республика } \\
\text { Коми }\end{array}$ & 165,3 & 301,8 & 375,9 & 421,0 & 447,3 & 454,2 & 514,9 & 505,1 & 519,3 \\
\hline
\end{tabular}

Рассчитано по данным Территориального органа Федеральной службы государственной статистики по Республике Коми [Электронный ресурс]. URL: http://komi.gks.ru/ (дата обращения: 10.12.2018)

Таблица 4

Факторы, определяющие темпы роста промышленного производства», \%

\begin{tabular}{|l|c|c|c|c|c|c|c|c|c|}
\hline \multirow{2}{*}{ Субъект РФ } & \multicolumn{7}{|c|}{ Исследуемый период } \\
\cline { 2 - 9 } & 2005 & 2010 & 2011 & 2012 & 2013 & 2014 & 2015 & 2016 & 2017 \\
\hline \multicolumn{8}{|c|}{ Вид экономической деятельности «Добыча полезных ископаемых» } \\
\hline РФ & 101,4 & 103,8 & 101,8 & 101,0 & 101,1 & 101,4 & 100,3 & 102,6 & 102,1 \\
\hline Республика Коми & 105,5 & 100,7 & 101,9 & 102,5 & 101,1 & 99,8 & 106,2 & 95,8 & 91,4 \\
\hline Вид экономической деятельности «Производство и распределение электроэнергии, газа и воды» \\
\hline РФ & 100,9 & 102,2 & 100,2 & 101,3 & 97,5 & 99,9 & 98,4 & 101,5 & 99,6 \\
\hline Республика Коми & 96,4 & 98,5 & 102,9 & 98,8 & 99,8 & 104,0 & 100,7 & 99,8 & 103,8 \\
\hline \multicolumn{8}{|c|}{ Вид экономической деятельности «Обрабатывающие производства» } \\
\hline РФ & 107,6 & 110,6 & 108,0 & 105,1 & 100,6 & 102,1 & 94,6 & 100,1 & 102,5 \\
\hline Республика Коми & 105,8 & 102,4 & 114,8 & 102,2 & 107,8 & 101,3 & 86,3 & 95,0 & 105,9 \\
\hline $\begin{array}{l}\text { Рассчитано по данным Территориального органа Федеральной службы государственной статистики } \\
\text { по Республике Коми [Электронный ресурс]. URL: httр://коті.gks.ru/ (дата обращения: 10.04.2018) }\end{array}$ \\
\hline
\end{tabular}

Третий фактор, оказавший влияние на состояние промышленности в республике, - темпы роста обрабатывающей промышленности. Здесь наблюдается тенденция роста (в 2017 г. по сравнению с 2016 г. рост составил 10\%) (табл. 4).

Главным фактором, сдерживающим развитие промышленности в Республике Коми, стало ограничение внутреннего спроса. Он происходит по двум ключевым каналам. Первый - в условиях роста реальных процентных ставок дестимулировалась инвестиционная и производственная активность, ухудшалось финансовое положение организаций. Ограничивался спрос на промежуточную и конечную продукцию. Второй - сдерживание социальных расходов в бюджетном секторе оказывало угнетающее воздействие на потребительский спрос. В этих условиях динамика развития промышленного производства почти целиком зависела от ситуации в сырьевом комплексе. Как только в добыче полезных ископаемых наметилось замедление темпов роста, вниз пошли темпы всего промышленного производства, а когда динамика добычи полезных ископаемых на фоне мер по ограничению добычи нефти вошла в область отрицательных значений, в промышленности сформировались условия для спада.

Эффективность промышленной политики оценим с использованием данных таблицы 5.

В анализируемом периоде имеет место устойчивый тренд роста объемов отгруженных товаров собственного производства, выполненных работ и услуг на душу населения как в РФ, так и Республике Коми (В 2017 г. по сравнению с 2005 г. в 4, 3 раза и 4,1 раза соответственно). 
Эффективность промышленной политики

\begin{tabular}{|c|c|c|c|c|c|c|c|c|c|}
\hline \multirow{2}{*}{ Субъект РФ } & \multicolumn{9}{|c|}{ Исследуемый период } \\
\hline & 2005 & 2010 & 2011 & 2012 & 2013 & 2014 & 2015 & 2016 & 2017 \\
\hline \multicolumn{10}{|c|}{$\begin{array}{c}\text { Объем отгруженных товаров собственного производства, } \\
\text { выполненных работ и услуг собственными силами на душу населения, руб. }\end{array}$} \\
\hline РФ & 83,5 & 175,6 & 215,6 & 238,2 & 251,6 & 268,9 & 316,4 & 326,3 & 358,4 \\
\hline Республика Коми & 143,1 & 297,3 & 382,1 & 436,8 & 467,2 & 475,5 & 549,7 & 540,3 & 576,5 \\
\hline \multicolumn{10}{|c|}{ Доля промышленности в ВРП, \% } \\
\hline Республика Коми & 87,1 & 75,5 & 77,9 & 80,3 & 84,5 & 84,9 & 90,0 & 84,0 & Н.д. \\
\hline \multicolumn{10}{|c|}{ Структура промышленного производства \% } \\
\hline \multicolumn{10}{|c|}{ Доля обрабатывающих производств в общем объеме промышленного производства, \% } \\
\hline Республика Коми & 42,3 & 33,1 & 35,9 & 34,9 & 35,3 & 35,5 & 34,1 & 32,5 & 31,5 \\
\hline \multicolumn{10}{|c|}{ Доля добывающих производств в общем объеме промышленного производства, \% } \\
\hline Республика Коми & 47,2 & 55,0 & 54,3 & 56,3 & 55,5 & 54,8 & 58,4 & 56,8 & 58,1 \\
\hline
\end{tabular}

Таблица 6

Доля обрабатывающих видов экономической деятельности в структуре ВРП в Республике Коми, \%

\begin{tabular}{|l|c|c|c|c|c|c|c|c|c|}
\hline \multirow{2}{*}{\multicolumn{1}{|c|}{ Субъект РФ }} & \multicolumn{7}{|c|}{ Исследуемый период } \\
\cline { 2 - 12 } & 2005 & 2010 & 2011 & 2012 & 2013 & 2014 & 2015 & 2016 & 2017 \\
\hline РФ & 49,2 & 50,1 & 50,2 & 50,3 & 49,6 & 50,1 & 53,9 & 42,0 & Н.д. \\
\hline Республика Коми & 11,7 & 9,7 & 11,5 & 10,7 & 11,4 & 10,7 & 11,3 & 11,7 & Н.д. \\
\hline
\end{tabular}

Рассчитано по данным Территориального органа Федеральной службы государственной статистики по Коми [Электронный ресурс]. URL: http://komi.gks.ru/ (дата обращения: 10.04.2018

Однако, вектор промышленного развития в республике неустойчивый. В последние годы наблюдается снижение доли промышленности в ВРП. Наметилось снижение доли обрабатывающих производств в общем объеме промышленного производства.

Для получения более объективной оценки состояния промышленного производства используется критерий - доля обрабатывающих производств в ВРП соответствующих субъектов. Эта доля должна быть не ниже 25\%. Представляется данный подход достаточно убедительным для констатации факта индустриального профиля территории (табл. 6) [1, c. 290].

Анализируя данные таблицы отметим, что доля обрабатывающих производств ниже порогового значения 11,7 вместо 25\%).

\section{Результаты исследования}

Оценка состояния промышленной политики в Республике Коми позволила сделать следующие выводы.

1. Приоритеты промышленной политики четко не обозначены в принятых нормативных правовых документах. Отсутствует долгосрочная Стратегия развития промышленности, в виде отдельного документа, показывающая направление движения обрабатывающих отраслей, повышение их доли в ВРП, предусматривающая в качестве приоритетов создание промышленных комплексов, таких как горнодобывающий, агропромышленный, строительный комплекс, а также комплексов в промышленности строительных материалов и легкой промышленности.

2. Вопросы промышленного развития решаются в рамках Закона Респу- 
блики Коми «О некоторых вопросах в сфере промышленной и инновационной политики в Республике Коми», который, как написано в преамбуле, регулирует только «некоторые вопросы формирования и реализации промышленной политики» [12] и не формулирует ее приоритетные цели и задачи, не обозначает инструменты реализации промышленной политики. Законодатели ограничились мерами стимулирования промышленной политики.

3. Промышленная политика ориентирована на внутренний рынок, что предполагает структурные изменения за счет импортозамещения. Однако мировой опыт нацеливает на ориентацию промышленной политики на завоевание экспортного рынка.

4. Маркетинговая программа развития территории и отрасли, нацеленная на улучшение имиджа территории и привлечение требуемых инвестиций, не разработана.

5. Вклад промышленности в ВРП сокращается, несмотря на это промышленность республики остается локомотивом ее экономического развития.

6. Доля обрабатывающих производств значительно ниже доли добывающих производств, и имеет тенденцию к снижению, что свидетельствует о разной степени адаптации видов экономической деятельности республики к трансформированной ситуации в экономике. Можно констатировать, что уровень добычи полезных ископаемых в регионе удовлетворяет, в общем, сегодняшние потребности национального и мирового рынка.

7. Доля обрабатывающих производств в ВРП в регионе сырьевой ориентации не превышает $25 \%$, что недостаточно для обеспечения саморазвития территории, то есть республика находится в состоянии управляемой деиндустриализации.

Новые тренды мирового экономического развития, связанные с наступлением четвертой промышленной революции, формируют новые требования к современной промышленной политике предопределяют необходимость модернизации промышленного производства, расширения доли продукции высокотехнологичных отраслей, ускорен- ного обновления основного капитала, в особенности в обрабатывающих видах экономической деятельности. В этих условиях целесообразно использование следующих инструментов для оздоровления промышленного производства:

1. Инвестиционные проекты в обрабатывающих отраслях, где соединяются административные, финансовые, инфраструктурные, технологические ресурсы. Такие проекты преследуют цели: создание в рамках отечественной экономики замкнутых цепочек добавленной стоимости, на выходе которых создается конкурентоспособный наукоемкий продукт; встраивание отечественных компаний в глобальные цепочки с участием зарубежных транснациональный компаний; формирование транснациональных компаний на базе отечественных.

2. Кластерный подход к формированию промышленной политики в обрабатывающих видах экономической деятельности, что усиливает конкурентные преимущества отдельных компаний и, следовательно, кластера в целом на основе синергетического эффекта. Для Республики Коми «полюсом роста» ее экономики, развития промышленного потенциала и повышения качества жизни населения является лесной сектор. Поэтому в качестве приоритетного направления определено формирование лесопромышленного кластера. Целевой установкой данной кластерной инициативы является адаптация традиционных отраслей промышленности к современным технологическим укладам за счет формирования источников роста инновационной экономики в рамках кластерных проектов, а также достижение глобальной конкурентоспособности обрабатывающей промышленности по отдельным направлениям [10, с. 187]. Серьезным потенциалом кластеризации в республике обладает нефтегазовая отрасль, что обуславливает целесообразность создания нефтегазового кластера, и позволит осуществлять углубленную переработку нефти и экспортировать не только сырую нефть, но и нефтепродукты, решить вопросы внедрения инноваций и импортозамещения.

3. Государственно-частное партнерство (ГЧП). ГЧП - это стратегический 
институциональный и организационный альянс государственной власти и частного бизнеса с целью реализации общественно значимых проектов в широком спектре сфер деятельности - от развития стратегически важных отраслей экономики до предоставления общественных услуг в масштабах всей страны или отдельных территорий [2, с. 126]. Данный институт позволяет скорректировать «провалы» рынка и государства. Государство перекладывает частично расходы по инвестированию на частный сектор, пользуется результатами более эффективного управления своей собственностью, сохраняет социально-значимые объекты в государственной собственности и под своим контролем, пользуется результатами предпринимательской инициативы. Частный бизнес получает в долговременное управление государственные активы на льготных условиях, снижает риски вложения инвестиций за счет получения государственных гарантий, возможность привлечения за счет гарантий большего объема финансовых ресурсов из бюджетов разного уровня, финансовых институтов развития, из банковского и реального секторов экономики, имеет возможность повышения капитализации и имиджа компании. Общество, как бенифициар, получает государственные услуги высокого качества по низким ценам, широкие возможности для решения острых социальных проблем. [2, с. 126-127]. В Республике Коми реализуется 8 инвестиционных проектов на условиях ГЧП. Основной источник их финансирования внебюджетные средства. Проекты реализуются на основе концессионного соглашения в соответствии с Ф3 «О концессионных соглашениях» и Ф3 «О государствен- но-частном партнерстве, муниципально-частном партнерстве в Российской Федерации и внесении изменений в отдельные законодательные акты Российской Федерации».

\section{Заключение}

Дальнейшие исследования должны исходить из посыла, что нужна ясная и понятная стратегия развития промышленности, в виде отдельного документа, показывающая направления движения обрабатывающих отраслей, повышения их доли в ВРП, предусматривающая в качестве приоритетов создание промышленных комплексов, таких как горнодобывающий, агропромышленный, строительный комплекс, а также комплексов в промышленности строительных материалов и легкой промышленности. Акцент нужно сделать на том, что для развития отраслей добывающей промышленности нужен рынок сбыта продукции, что обуславливает необходимость развития инфраструктуры и логистики. Для достижения поставленных целей требуются инвестиции, привлечь которые без изменения имиджа территории невозможно. Поэтому нужна маркетинговая программа развития территории и отрасли.

Намеченные меры выстраивают системный подход для принятия эффективных управленческих решений по обеспечению устойчивого роста и поступательного развития региона. Они адекватны сложившейся ситуации, направлены на поиск возможностей развития несырьевого сектора экономики, развитие обрабатывающей промышленности, их успешное осуществление обеспечит Республике Коми нивелирование проблем социально-экономического развития.

\section{Библиографический список}

1. Акбердина В.В., Гребенкин А.В., Бухвалов Н.Ю. Моделирование инновационного резонанса в индустриальных районах // Экономика региона. - 2015. - № 4. - С. 289-308.

2. Завадников В.О. О промышленной политике в Российской Федерации // Промышленная политика в Российской Федерации. - 2007. - № 5. - С. 19-31.

3. Зедина Ю. Государственно-частное партнерство в стратегии инновационного развития российских регионов // Федерализм. - 2013. - № 1. - С. 121-130.

4. Идрисов Г.И. Промышленная политика России в современных условиях. - М.: Изд-во Ин-та Гайдара, 2016. - 160 c.

5. Industrial Policy for the twenty-first century. (November 2004). CEPR Discussion Paper No. 4767. Available at SSRN: http://ssrn.com/abstract $=666808$. 
6. Кислицына В.В., Чеглакова Л.С. Караулов В.М., Чикишева А.Н. Формирование комплексного подхода к оценке социально-экономического развития регионов // Экономика региона. - 2017. T. 13(2). - С. 369-380.

7. Кондратьев В. Промышленная политика или политика конкурентоспособности. Структурные и секторальные аспекты. Качество роста. Направления конкурентоспособного роста. - М.: Фонд комплексных прикладных исследований, 2003. - 209 с.

8. Krugman P.R., Obstfeld M. International economics: Trade and policy. (7th ed.). Boston: Pearson ddison Wesley, 2006.

9. Научно-технологическая, инвестиционная, инновационная и промышленная политика: энциклопедический словарь / под общ. ред. В.В. Ивантера. - М., 2011.

10. Новокшонова Е.Н. Оценка региональной инвестиционной политики как инструмента создания промышленных кластеров в условиях Севера. - М.: Экон-Информ, 2015. - 234 с.

11. Федеральный закон РФ от 31 декабря 2014 г. N 488-Ф3 «О промышленной политике в Российской Федерации». [Электронный ресурс]: СПС КонсультантПлюс. - URL: http//www.consultant. ru (дата обращения 20.01.2019 г.).

12. Закон Республики Коми от 31.10.2017 N 78-P3 «О некоторых вопросах в сфере промышленной и инновационной политики в Республике Коми». [Электронный ресурс]: СПС КонсультантПлюс. - URL: http//www.consultant.ru (дата обращения 20.01.2019 г.).

13. Портер М. Конкуренция / пер. с англ. - М.: Издательский дом «Вильямс», 2005. - 608 с.

14. Price V.C. Industrial policies in the European Community // Macmillan for the Trade Policy Research Centre. - 1981. - Vol. 4.

15. Rodrik D. Industrial Policy the Twenty-First Century. Harvard Universitety. 2004. [Electronic reseurse]. - URL: http: // www. Hks.harvard.edu /fs/Rodrik/Research\%20papers/ UNIDOSSep.pdf .

16. Романова О.А., Сиротин Д.В. Образ желаемого будущего экономики индустриального региона: тенденции развития и методология оценки // Экономика региона. - 2017. - Т. 13(3). - С. 746-763.

17. Смирнов Е. Инновационный вектор промышленной политики Европейского Союза // Международная экономика. - 2007. - № 2. - С. 54-59.

18. Татаркин А.И., Романова О.А. Промышленная политика: генезис, региональные особенности и законодательное обеспечение // Экономика региона. - 2014. - № 2. - С. 9-21.

19. Татаркин А.И., Романова О.А. Промышленная политика и механизм ее реализации: системный подход // Экономика региона. - 2007. - № 3. - С. 19-31.

20. UNIDO. Industrial Development Report. UNIDO, 2013. 